\title{
Heat shock proteins play a crucial role in tumor-specific apoptosis by REIC/Dkk-3
}

\author{
FERNANDO ABARZUA ${ }^{1,2}$, MASAKIYO SAKAGUCHI ${ }^{2}$, RYUTA TANIMOTO ${ }^{1}$, HIROYUKI SONEGAWA ${ }^{2}$, \\ DAI-WEI LI ${ }^{2}$, KOHEI EDAMURA ${ }^{1}$, TOMOKO KOBAYASHI ${ }^{1}$, MASAMI WATANABE ${ }^{1}$, \\ YUJI KASHIWAKURA ${ }^{1}$, HARUKI KAKU ${ }^{1}$, TAKASHI SAIKA ${ }^{1}$, KEIICHIRO NAKAMURA ${ }^{3}$, \\ YASUTOMO NASU ${ }^{1}$, HIROMI KUMON ${ }^{1}$ and NAM-HO HUH $^{2}$ \\ ${ }^{1}$ Departments of Urology, ${ }^{2}$ Cell Biology and ${ }^{3}$ Obstetrics and Gynecology, Okayama University \\ Graduate School of Medicine, Dentistry, and Pharmaceutical Sciences, Shikata-chou, Okayama 700-8558, Japan
}

Received December 29, 2006; Accepted February 20, 2007

\begin{abstract}
We recently showed that overexpression of REIC/ Dickkopf-3 (Dkk-3), a tumor suppressor gene, induced apoptosis in a tumor cell-specific manner. The aim of the present study was to determine the mechanisms underlying the selective induction of apoptosis. At first, we found a mouse renal carcinoma cell line, RENCA, to be extremely sensitive to an adenovirus carrying REIC/Dkk-3 (Ad-REIC), and we showed that activation of c-Jun N-terminal kinase (JNK) was a critical step in cell death, i.e. a process similar to that in human prostate and testicular cancer observed in our previous studies. Among the proteins interfering with the activation of JNK, heat shock protein (Hsp)70/72 was reduced in expression in RENCA cells compared with that in NIH3T3 cells. An Hsp70/72 inducer protected RENCA cells from Ad-REIC-induced apoptosis, while an Hsp70/72 inhibitor sensitized NIH3T3 cells for apoptosis induction. These results indicate that functionally active Hsp70/72 is a key factor in tumor cell-specific induction of apoptotic cell death and that analyses of the expression levels of Hsp70/72 may be essential in determining the significance of Ad-REICbased gene therapy against human cancer.
\end{abstract}

\section{Introduction}

The Dickkopf (Dkk) family is composed of 4 members, Dkk$1-4$, that show distinct as well as similar biological functions (1). Dkk-1 and -4 are known to interfere with Wnt signaling through the common receptor LRP5/6 (1-4). Since the Wnt

Correspondence to: Dr N. Huh, Department of Cell Biology, Okayama University Graduate School of Medicine, Dentistry, and Pharmaceutical Sciences, 2-5-1 Shikata-cho, Okayama 700-8558, Japan

E-mail: namu@md.okayama-u.ac.jp

Key words: REIC, Dickkopf-3, testicular tumor, therapy signal pathway has been shown to be aggravated in many types of cancers (5-7), Dkk-1 is thought to behave as a tumor suppressor gene. Expression of endogenous Dkk-1 was shown to be reduced in human melanomas (8), and forced expression of Dkk-1 resulted in increased apoptosis of various tumor cells (9-11). Unlike Dkk-1 and -4, REIC/Dkk-3 does not bind to LPR5/6 or interfere with Wnt signaling $(12,13)$. Nevertheless, expression of the REIC/Dkk-3 gene is suppressed in cells and tissues of many human cancers, including prostate cancer, renal clear cell carcinoma and nonsmall cell lung cancer (14-16). More notably, expression of REIC/Dkk-3 using an adenovirus vector (Ad-REIC) selectively induced apoptosis in human prostate cancer cell lines (16) and a human testicular cancer cell line (17) with only a marginal effect on normal counterparts. Furthermore, human prostate cancer cells transplanted subcutaneously into nude mice were completely regressed in 4 out of 5 animals by a single injection of Ad-REIC (16). The selective action of REIC/Dkk-3 is of profound significance and prompts further mechanistic study since the selective killing of malignant cells is the most critical issue for successful treatment of human cancer.

Our previous study showed that a membrane-permeable Bax inhibitor V5 completely abrogated the apoptosis induced in the prostate cancer cell line PC3 by infection with AdREIC (16). Translocation of Bax protein from the cytoplasm to the mitochondria, a hallmark of the triggering of a Baxmediated apoptotic pathway, was completely suppressed by V5. The Ad-REIC infection activated c-Jun N-terminal kinase (JNK), one of the upstream activators of Bax in PC3 cells but not in normal human fibroblasts. The JNK-specific inhibitor SP600125 remarkably abrogated the Ad-REICinduced apoptosis of PC 3 cells in a dose-dependent manner. These results indicate that overexpression of REIC/Dkk-3 activates JNK in a malignant cell-specific manner, induces mitochondrial translocation of Bax protein, and leads to apoptotic cell death. In the present study, we analyzed the mechanism of the cell type-specific activation of JNK by AdREIC after identification of a cell line highly sensitive to the Ad-REIC-induced apoptosis and thus suitable for the mechanistic study. 


\section{Materials and methods}

Cells and reagents. RENCA, a renal cortical adenocarcinoma cell line of BALB/c mouse origin, was kindly provided by Dr Masatoshi Eto, Kyushu University. NIH3T3 cells were purchased from ATCC. RENCA and NIH3T3 cells were maintained in Dulbecco's modified Eagle's medium (MEM) and RPMI-1640 (Gibco), respectively, supplemented with $10 \%$ FBS (Gibco). A c-Jun N-terminal kinase (JNK) inhibitor, SP600125, was purchased from BioMol (Plymouth Meeting, PA, USA). A heat shock protein (Hsp) 70 inducer, geranylgeranylacetone, and an Hsp70/72 inhibitor (heat shock protein inhibitor I) were purchased from Eisai (Tokyo, Japan) and Calbiochem (La Jolla, CA, USA), respectively.

Immunocytochemistry. Cells were fixed with ethanol or with $4 \%$ paraformaldehyde and immunostained with four different anti-human REIC/Dkk-3 antibodies raised in our laboratory against full-length REIC/Dkk-3 and the N-terminal and Cterminal peptides. The specimens were then treated with Alexa fluor R594-conjugated goat anti-rabbit IgG antibody (Molecular Probes, Eugene, OR, USA) and mounted in Vectashield R with DAPI (Vector Laboratories, Burlingame, CA).

Overexpression of REIC/Dkk-3 and monitoring of apoptotic cells. REIC/Dkk-3 was overexpressed by infecting cells with an adenovirus vector carrying REIC/Dkk-3 (Ad-REIC) as described previously (16). A vector carrying LacZ (Ad-LacZ) was used as a negative control. Thirty-six hours after infection with the virus vectors at $20 \mathrm{MOI}$, apoptotic cells were monitored either by the TUNEL method using an In Situ Cell Death Detection kit (Roche) or by using a LIVE/DEAD Viability/Cytotoxicity kit (Invitrogen).

Immunoprecipitation and Western blot analysis. Total cell lysates were prepared at $36 \mathrm{~h}$ after adenovirus vector infection with a Triton X-100 lysis buffer $(150 \mathrm{mM} \mathrm{NaCl}, 1 \mathrm{mM}$ EDTA, $1 \%$ Triton $\mathrm{X}-100,10 \mu \mathrm{g} / \mathrm{ml}$ leupeptin, $10 \mu \mathrm{g} / \mathrm{ml}$ aprotinin and $200 \mu \mathrm{g} / \mathrm{ml}$ phenylmethanesulfonyl fluoride, $10 \mathrm{mM}$ Tris, $\mathrm{pH}$ 7.3). After saving aliquots of the samples for direct Western blot analysis, the cell lysates were cleared by treatment with excess amounts of TrueBlot ${ }^{\mathrm{TM}}$ anti-rabbit Ig IP beads (eBioscience, San Diego, CA) and incubated with rabbit anti-JNK/SAPK antibody (Cell Signaling) at $4^{\circ} \mathrm{C}$ for $120 \mathrm{~min}$. JNK and its associated proteins were recovered using TrueBlot anti-rabbit Ig IP beads. Western blot analysis was performed under conventional conditions. The antibodies used were as follows: rabbit anti-human REIC/Dkk-3 antibodies raised in our laboratory, a rabbit anti-human c-Jun antibody, a rabbit anti-human phospho-c-Jun (Ser63) antibody, a rabbit anti-human SAPK/JNK antibody, a rabbit antihuman phospho-SAPK/JNK (Thr183/Tyr185) antibody, a rabbit anti-human Hsp70/72 antibody (Cell Signaling Technology, Beverly, MA), a mouse monoclonal anti-human Hsp70/72 antibody (BD Biosciences), a mouse monoclonal anti-human Hsc70 antibody (Santa Cruz), and a mouse monoclonal anti-human $\beta$-actin antibody (Sigma).

In vitro binding assay. Human Hsp70/72 cDNA was cloned and inserted into a pGEX6P3 vector (GE Health Care

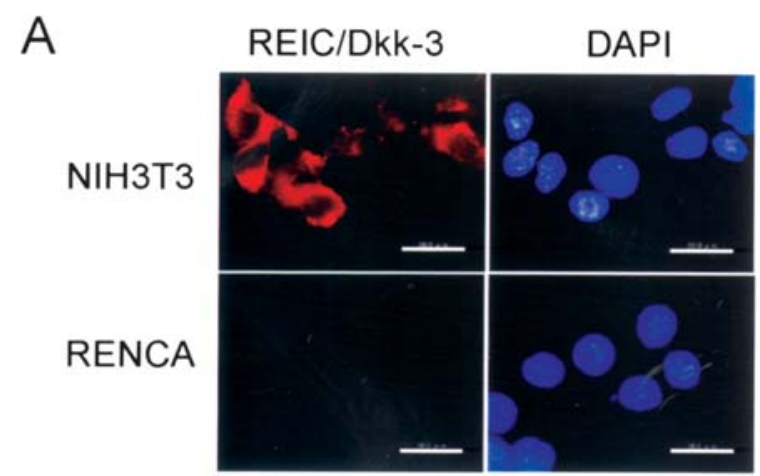

B

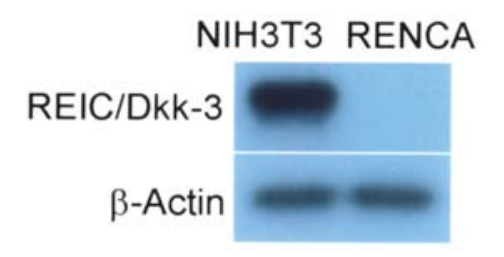

Figure 1. Expression of REIC/Dkk-3 in a mouse renal cancer cell line RENCA, and a normal fibroblastic cell line NIH3T3. (A) Immunohistochemistry for REIC/Dkk-3 using an antibody against the N-terminal region of REIC protein (shown in red) and nuclear staining with DAPI. Scale bars, $20 \mu \mathrm{m}$. (B) Western blot analysis for REIC/Dkk-3 in RENCA and NIH3T3 cells. B-actin was used as a control for the applied amount of protein.

Biosciences). The Hsp70/72 protein was expressed as a GSTfused protein and purified using glutathione sepharose 4B (GE Health Care Biosciences). Fifty micromolars each of GST-Hsp70/72, JNK $1 \alpha 1$ (active, Upstate), and JNK $1 \alpha 1$ (inactive, Upstate) were incubated in PBS for $1 \mathrm{~h}$ at room temperature, recovered using glutathione sepharose 4B, and analyzed by Western blotting for JNK.

\section{Results and discussion}

Lack of REIC/Dkk-3 expression in RENCA cells. We first examined expression of the REIC/Dkk-3 gene in RENCA cells in comparison with that in NIH3T3 cells. Immunocytochemistry for REIC/Dkk-3 using two antibodies against full-length REIC/Dkk-3 protein, an antibody against an Nterminal region, and an antibody against a C-terminal region, consistently revealed a positive signal in the cytoplasm of NIH3T3 cells but never in RENCA cells (Fig. 1A). The lack of expression of REIC/Dkk-3 in RENCA cells was confirmed by Western blot analysis (Fig. 1B). This observation accords well with results of our previous studies showing that REIC/ Dkk-3 levels were reduced in tumor cells and tissues derived from various human organs, including the kidney (15) and prostate (16).

Specific induction of apoptosis in RENCA cells by overexpression of REIC/Dkk-3. Since our previous study showed that overexpression of REIC/Dkk-3 induced apoptosis in cancer cells but not in normal cells $(16,17)$, we examined its effect on RENCA and NIH3T3 cells. We infected the cells with either Ad-LacZ or Ad-REIC at 20 MOI and monitored apoptotic cells by TUNEL staining $36 \mathrm{~h}$ after the infection. 
A
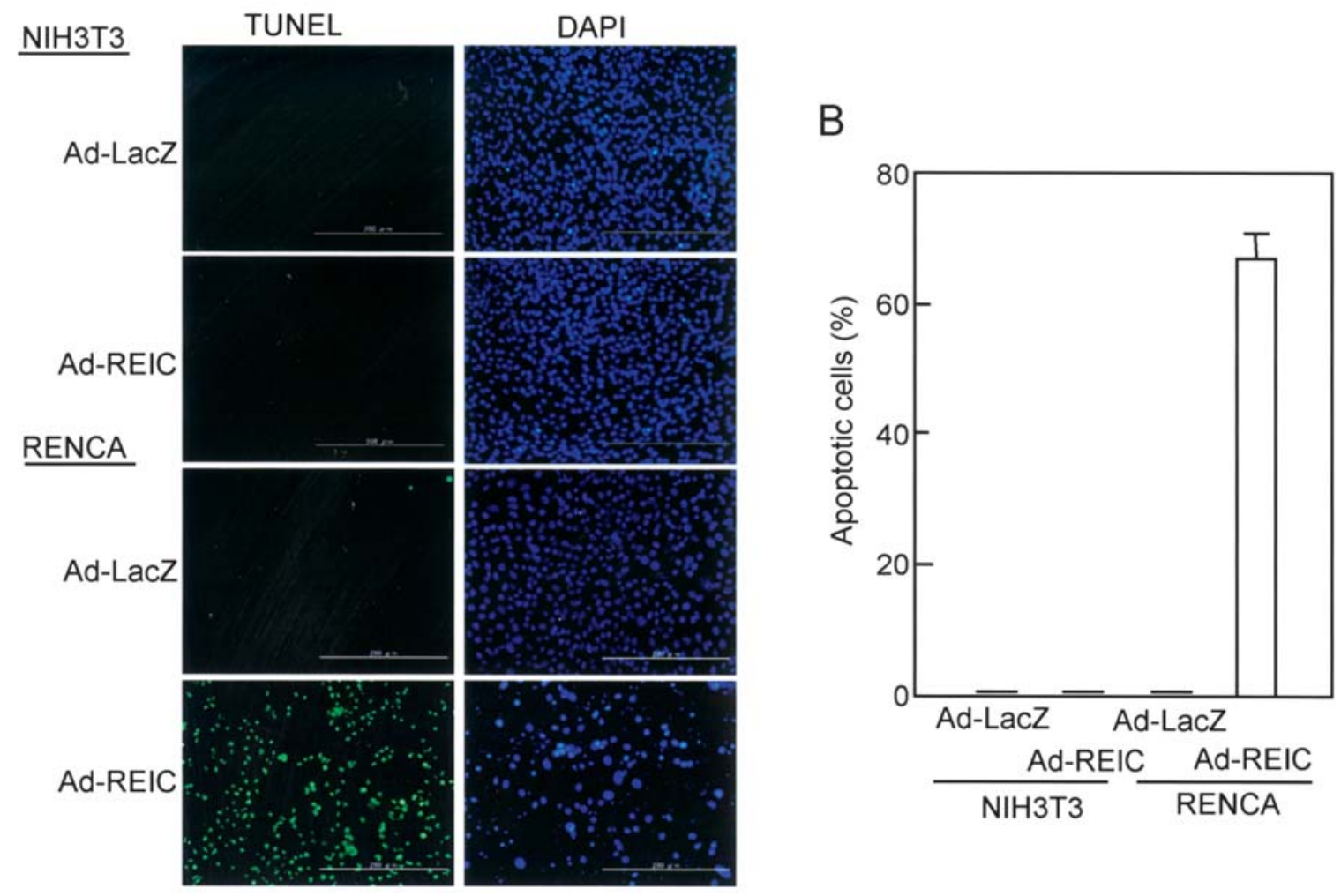

Figure 2. Induction of apoptotic cell death of RENCA cells by overexpression of REIC/Dkk-3. The cells were infected with Ad-LacZ or Ad-REIC at 20 MOI. (A) TUNEL staining for monitoring apoptotic cells and DAPI staining for nuclei $36 \mathrm{~h}$ after infection. Scale bars, $200 \mu \mathrm{m}$. (B) Quantitation of the TUNELpositive cells shown in A. Vertical bars, standard deviation.

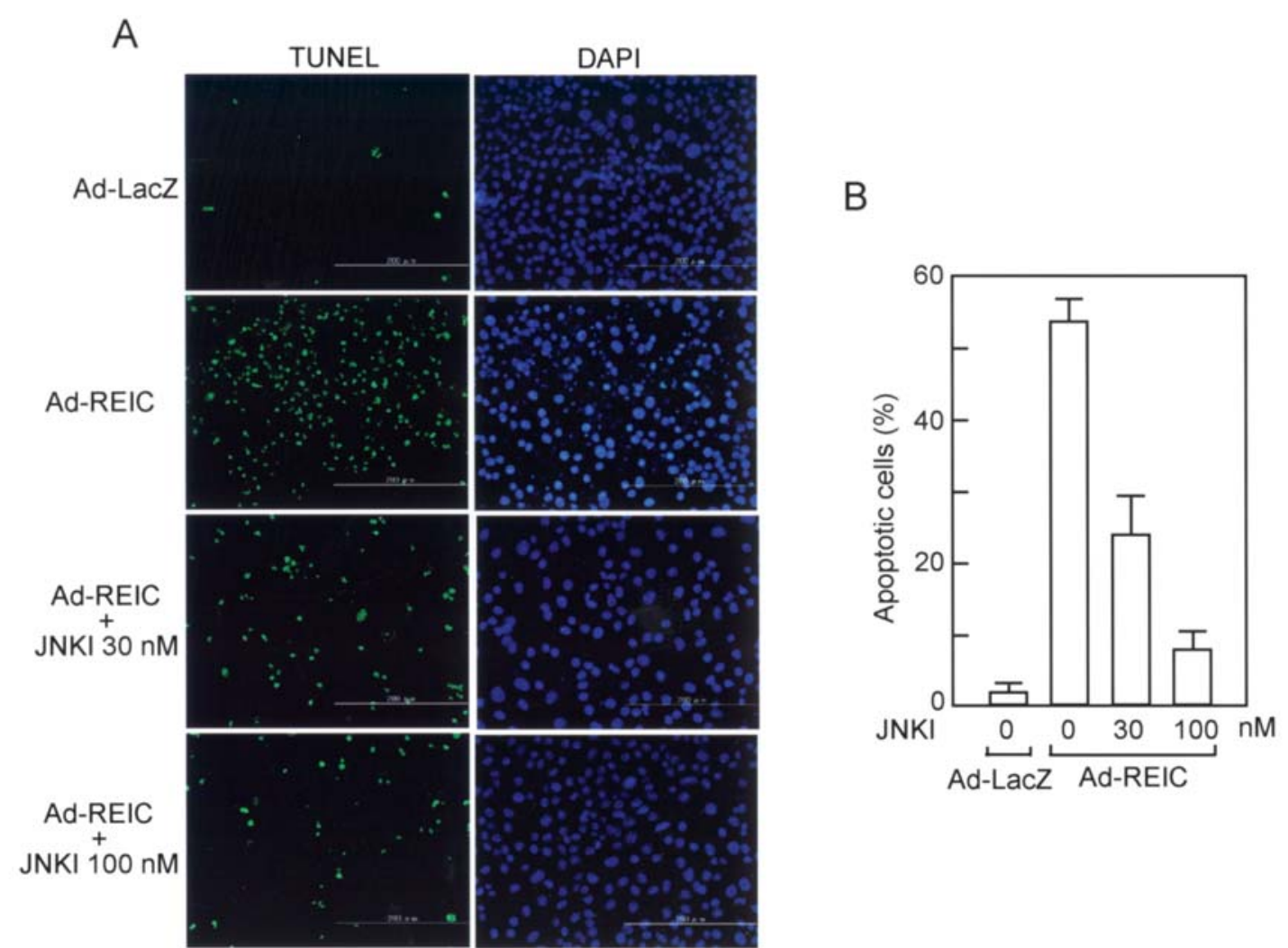

Figure 3. Abrogation of Ad-REIC-induced apoptosis of RENCA cells by a JNK inhibitor SP600125 (JNKI). RENCA cells were infected with Ad-LacZ or Ad-REIC at 20 MOI. The JNK inhibitor was added to the culture immediately after the infection, and the cells were fixed and stained $36 \mathrm{~h}$ after infection. (A) TUNEL staining for monitoring apoptotic cells and DAPI staining for nuclei. Scale bars, $200 \mu \mathrm{m}$. (B) Quantitation of the TUNEL-positive cells shown in A. Vertical bars, standard deviation. 
A

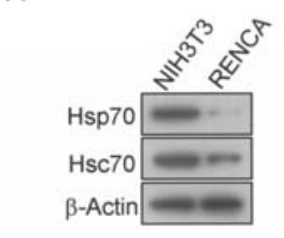

C

$\frac{\text { NIH3T3 }}{\text { Ad-LacZ Ad-REIC }} \frac{\text { RENCA }}{\text { Ad-LacZ Ad-REIC }}$
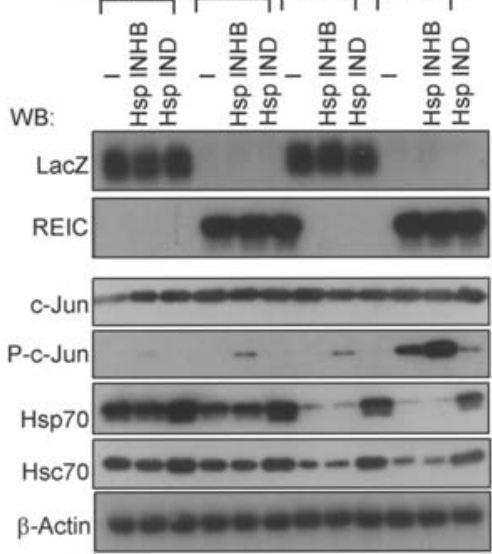

B

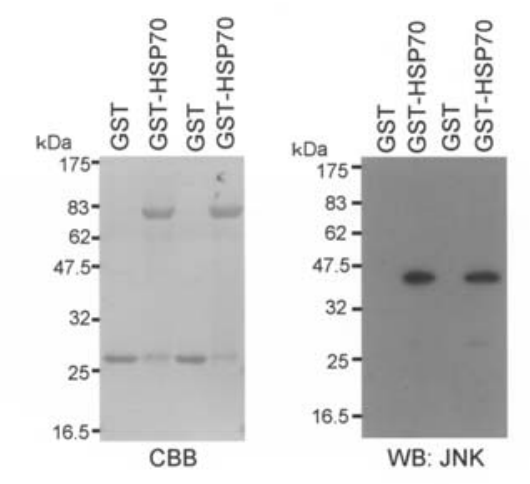

D

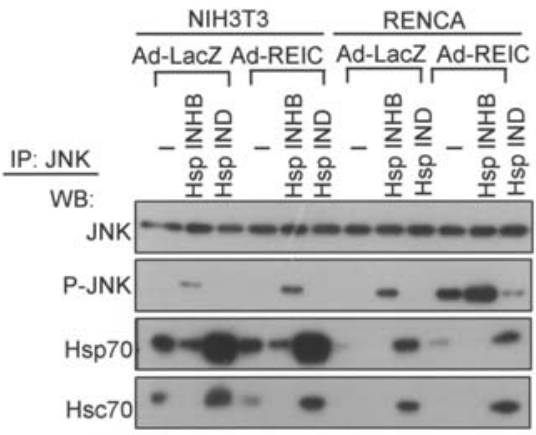

Figure 4. JNK and heat shock proteins (Hsp) in NIH3T3 and RENCA cells. (A) Expression levels of Hsp70/72 and Hsc70 in NIH3T3 and RENCA cells determined by Western blot analysis. B-actin was used as a control for the applied amounts of protein. (B) Direct binding of JNK to Hsp70/72 in vitro. Left panel: recombinant human Hsp70/72 was produced in a GST-fused form and purified using glutathione sepharose. GST was used as a negative control. Proteins were recovered, electrophoresed, and visualized on a PVDF membrane by CBB staining. Right panel: GST-Hsp70/72 was mixed with a mixture of active and inactive JNK proteins (Upstate) and pulled down with glutathione sepharose. The bound fraction of JNK proteins was detected by Western blot analysis. The experiments were performed in duplicate. (C,D) Analysis of JNK and heat shock proteins in REIC-overexpressed cells exposed to Hsp modulators. NIH3T3 and RENCA cells were infected with Ad-LacZ or Ad-REIC at 20 MOI. An Hsp inhibitor (Hsp INHB) (50 $\mu$ M) was added immediately after the virus infection. An Hsp inducer (Hsp IND) $(10 \mu \mathrm{M})$ was added $8 \mathrm{~h}$ prior to the infection followed by repeated addition of the same dose every $8 \mathrm{~h}$ over the cultivation period. The cells were harvested at $36 \mathrm{~h}$ after the infection. (C) Western blot analysis for indicated proteins, P-c-Jun and phosphorylated c-Jun protein. B-actin was used as a control for the applied amount of protein. (D) Proteins were immunoprecipitated with an anti-JNK antibody from the same cell extracts as in A and then analyzed by Western blotting. P-JNK, phosphorylated JNK protein.

Similar expression levels of exogenous REIC/Dkk-3 protein were confirmed in NIH3T3 and RENCA cells (Fig. 4C). As shown in Fig. 2, however, 67\% of Ad-REIC-infected RENCA cells were positive for TUNEL staining, while only $0.3 \%$ of Ad-REIC-infected NIH3T3 cells were positive. Ad-LacZ exerted a negligible effect on both RENCA and NIH3T3 cells. The highly sensitive and selective feature of REIC/Dkk-3-induced apoptosis in RENCA cells provides a suitable condition for a mechanistic study on tumor-specific induction of apoptosis by overexpression of REIC/Dkk-3 observed in a variety of malignant cells and tissues.

Involvement of JNK in Ad-REIC-induced apoptosis in RENCA cells. Our previous studies showed that JNK plays a major role in the induction of apoptosis by overexpression of REIC/ Dkk-3 in human cancer cells (16). To determine whether this is also the case in RENCA cells, we examined the effect of a JNK inhibitor on Ad-REIC-induced cell death in RENCA cells (Fig. 3). The JNK inhibitor SP600125 added to the cultures immediately after the virus infection dose-dependently abrogated the Ad-REIC-induced apoptotic cell death in RENCA cells, i.e. 30 and $100 \mathrm{nM}$ of SP600125 reduced apoptotic cell rate in the untreated cells by 56 and $86 \%$, respectively (Fig. 3B), indicating a critical role of JNK in the apoptotic process. In accordance with this, JNK was shown to be activated in RENCA cells by infection with Ad-REIC but not by infection with Ad-LacZ as demonstrated by phosphorylation of JNK itself and its substrate c-Jun (Fig. 4C). Neither JNK nor its substrate c-Jun was phosphorylated by Ad-REIC in NIH3T3 cells, where no induction of cell death was observed. A critical question to be addressed for understanding the mechanisms of the tumor-specific induction of apoptosis, therefore, is why and how JNK was activated in RENCA cells but not in NIH3T3 cells despite the fact that both types of cells were similarly infected with Ad-REIC.

Activation of JNK was also shown to be a key event in Dkk-1-induced apoptosis by Lee et al (11). Although Dkk-1 interferes with Wnt signaling, the activation of JNK by Dkk-1 did not involve the canonical Wnt signal pathway since they used a cell line lacking both alleles of B-catenin. REIC/Dkk-3 is known not to interfere with Wnt signaling $(12,13)$. We showed that the protein level and intracellular localization of ß-catenin remained unchanged in PC3 cells when the cells 
A

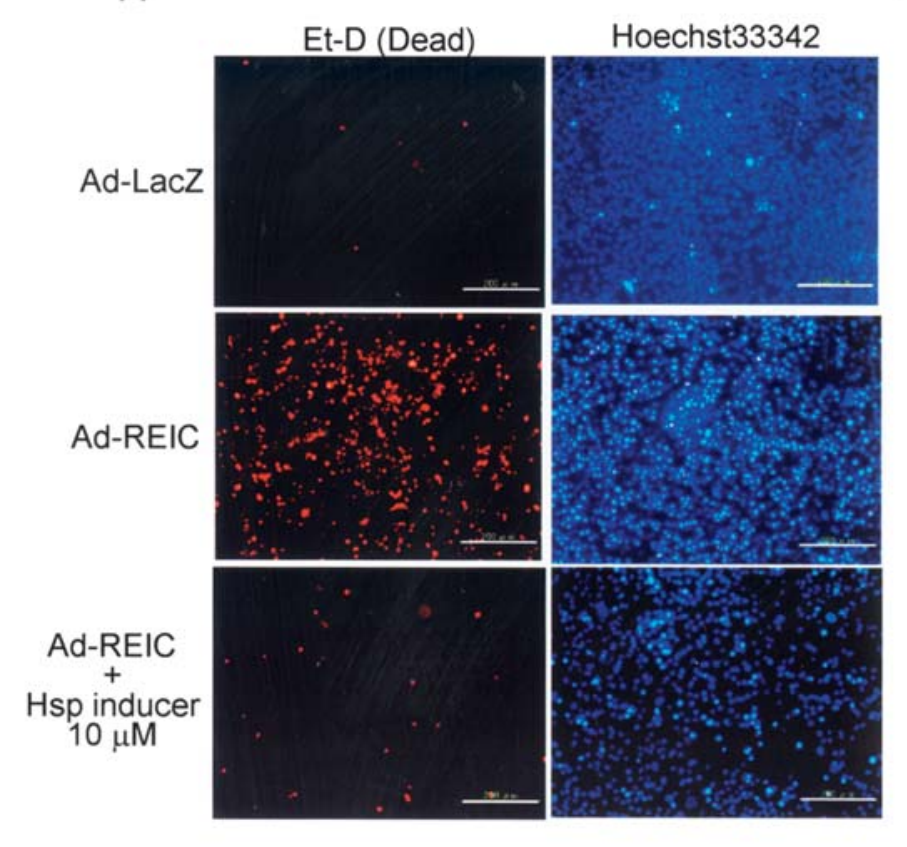

B

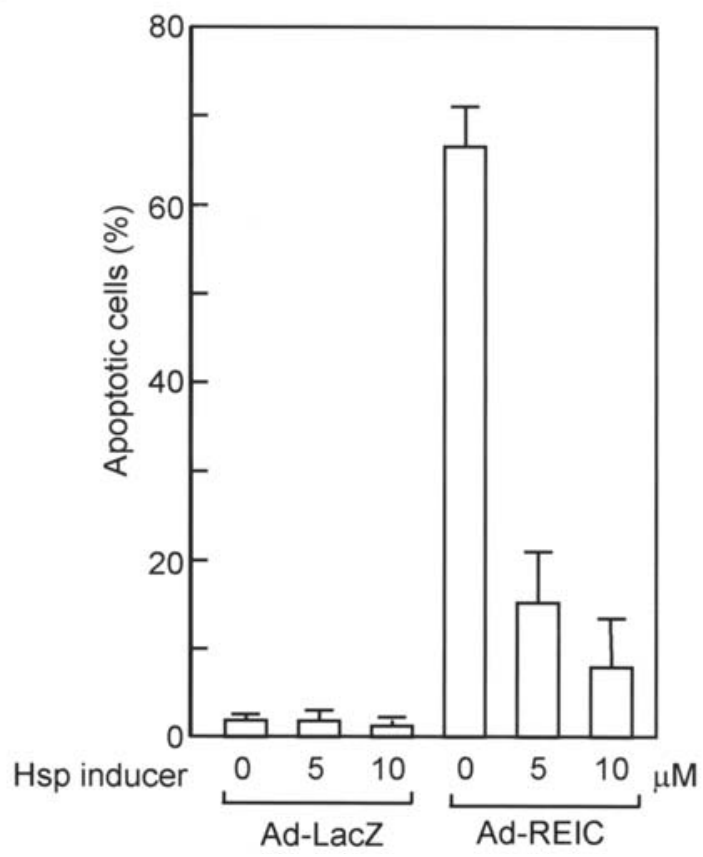

Figure 5. Inhibition of REIC-induced apoptotic cell death of RENCA cells by an Hsp inducer. RENCA cells were treated under the same conditions as those described in the legend of Fig. 4, and viability of the cells was examined using a LIVE/DEAD Viability/Cytotoxicity kit (Cambrex), in which dead cells were stained red with ethidium bromide dimer (Et-D) and all cell nuclei were stained blue with Hoechst 33342. (A) Dead cells and all cell nuclei were stained in red and blue, respectively. Scale bars, $200 \mu \mathrm{m}$. (B) Quantitation of the apoptotic cells shown in A. Vertical bars, standard deviation.

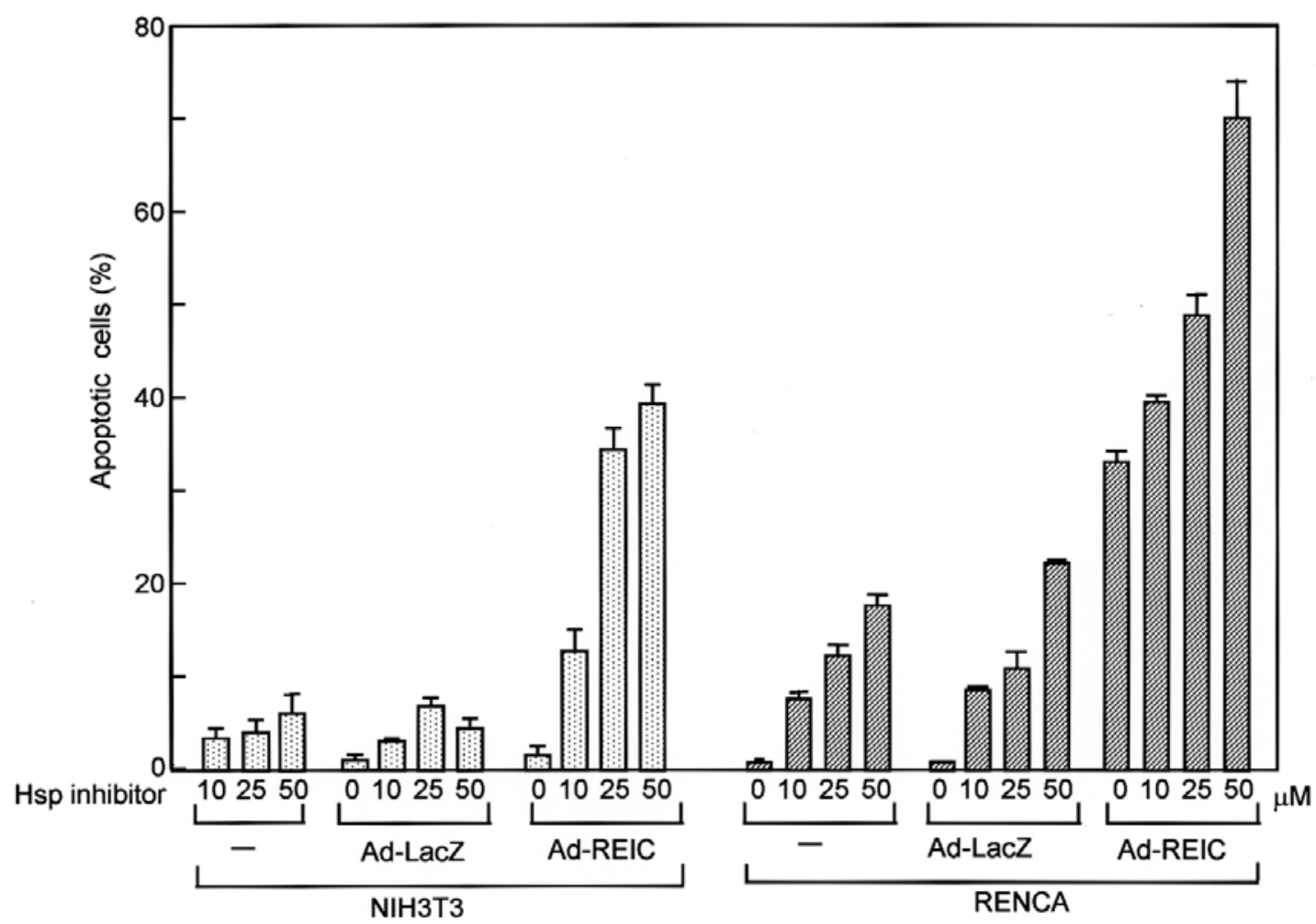

Figure 6. Sensitization of NIH3T3 and RENCA cells to REIC-induced apoptotic cell death by an Hsp inhibitor. The cells were treated under the same conditions as those described in the legend of Fig. 4, and viability of the cells was determined by the same method as that described in the legend of Fig. 5 . Vertical bars, standard deviation.

were infected with Ad-REIC and were undergoing apoptotic cell death (16). An alternative and more likely possibility is that Ad-REIC-induced apoptosis may take place through activation of a stress-sensing mechanism for overload of specific proteins known as endoplasmic reticulum (ER) stress. It is well established that JNK is a key molecule leading 
cells in ER stress to apoptotic cell death, and inhibition of JNK abrogates the induction of apoptosis $(18,19)$.

Heat shock proteins (Hsps) as a key factor for tumor-specific apoptosis by Ad-REIC. A number of different proteins are known to bind to and inhibit the activity of JNK, including Hsp70/72, p21(WAF1), Rb, and GSTp (20-23). Among these, we focused on Hsp70/72 since the protein level of Hsp70/72 was reduced in RENCA cells compared with that in NIH3T3 cells (Fig. 4A). Expression of a constitutively expressed Hsc70 was also reduced in RENCA cells, though to a lesser extent. Recombinant Hsp70/72 directly bound to JNK in vitro (Fig. 4B). Binding of endogenous JNK and Hsp70/72 or Hsc70 was confirmed by immunoprecipitation followed by Western blot analysis (Fig. 4D). Hsp90 and Hsp27 were expressed at lower levels in NIH3T3 cells than in RENCA cells, but neither protein interacted with JNK and hence were not considered to play significant roles in the present context (data not shown).

If the reduced Hsp70/72 level in RENCA cells is causatively linked to the sensitivity to Ad-REIC-induced apoptosis, induction of Hsp70/72 should suppress the apoptotic death of the cells. When RENCA cells were treated with the Hsp70/72 inducer geranylgeranylacetone at $10 \mu \mathrm{M}$, Hsp70/72 was induced to a level slightly less than that of untreated NIH3T3 cells (Fig. 4C). The induction of Hsp70/72 resulted in abrogation of activation of JNK (Fig. 4C) and of apoptotic cell death (Fig. 5) by Ad-REIC infection. The apoptotic cell rate determined $36 \mathrm{~h}$ after the Ad-REIC infection was reduced from $66.5 \%$ in untreated RENCA cells to 15.1 and $7.9 \%$ in the cells treated with 5 and $10 \mu \mathrm{M}$ of geranylgeranylacetate, respectively (Fig. 5B).

On the other hand, exposure of cells to an Hsp70/72 inhibitor sensitized NIH3T3 cells to apoptosis induction by Ad-REIC in a dose-dependent manner from 10-50 $\mu \mathrm{M}$ (Fig. 6). The ratios of apoptotic cells were only $1.6 \%$ in NIH3T3 cells simply infected with Ad-REIC and 39.1\% in the cells treated with $50 \mu \mathrm{M}$ of an Hsp70/72 inhibitor in addition to the virus infection (Fig. 6). JNK was activated as assessed by detecting phosphorylated c-Jun in Ad-REICinfected NIH3T3 cells treated with $50 \mu \mathrm{M}$ of the inhibitor but not in the untreated cells (Fig. 4C). Treatment with the Hsp70/72 inhibitor dose-dependently induced apoptosis even in non-infected and Ad-LacZ-infected RENCA cells and reinforced apoptotic cell death in Ad-REIC-infected cells (Fig. 6). These results indicate that the tumor cell-specific apoptosis induced by overexpression of REIC/Dkk-3 was mainly due to the functional difference of Hsp70/72.

Hsp70/72 has been shown to inhibit apoptosis induced by a broad variety of agents, including stresses (24-28). Although Park et al (20) demonstrated that Hsp72(70) inhibited heat-induced activation of JNK through direct interaction in NIH3T3 cells, many lines of evidence indicate that the mechanism of anti-apoptotic action of Hsp70/72 is pleiotropic depending on cell type and apoptotic stimuli. Hsp70/72 prevented stress-induced apoptosis of a human T-lymphocyte cell line by acting not only on JNK but also at some point downstream of JNK (27). Buzzard et al (28) showed that constitutively expressed Hsp70/72 inhibited apoptosis of mouse embryonic fibroblasts by heat, ceramide, or TNF $\alpha$ but did not affect JNK activity. Hsp70/72 exerted its anti-apoptotic action not at the stage of JNK but at a downstream step of caspase 3-like proteases (29).

In the present study, we obtained evidence that the functional state of Hsp70/72 correlates well with resistance to apoptosis induced by overexpression of REIC/Dkk-3. Our preliminary screening revealed that human cancer cells largely differ in sensitivity to Ad-REIC-induced apoptosis and that the sensitivity depends on expression levels of anti-apoptotic proteins, including Hsp70/72. The results of the present study may contribute to the establishment of a convenient and reliable method to distinguish the sensitivity of different human tumors to gene therapy using Ad-REIC.

In conclusion, through the present study we analyzed the mechanism of tumor cell-specific induction of apoptosis by Ad-REIC using a cell line highly sensitive to apoptosis induction. Among the proteins interfering with the activation of JNK, a critical event for Ad-REIC-induced apoptosis was the reduced expression of Hsp 70/72 in RENCA cells compared with that in NIH3T3 cells. An Hsp70/72 inducer protected RENCA cells from Ad-REIC-induced apoptosis, while an Hsp70/72 inhibitor sensitized NIH3T3 cells for apoptosis induction. These results indicate that functionally active Hsp70/72 is a determining factor for tumor cellspecific induction of apoptotic cell death and that analyses of the expression levels of Hsp70/72 may contribute to the identification of human cancers sensitive to gene therapy using Ad-REIC.

\section{Acknowledgements}

This study was financially supported by Grant-in-Aid for Scientific Research from the Japan Society for the Promotion of Science [B(2) 18390437, Y. Nasu; C 18591249, D-W. Li], Health and Labor Sciences Research Grant from the Ministry of Health, Labor and Welfare (Third Term Comprehensive Control Research for Cancer, H. Kumon), and Special Coordination Funds for Promoting Science and Technology (H. Kumon). We would like to thank Mr. Hideo Ueki for the technical assistance.

\section{References}

1. Kawano Y and Kypta R: Secreted antagonists of the Wnt signalling pathway. J Cell Sci 116: 2627-2634, 2003.

2. Bafico A, Liu G, Yaniv A, Gazit A and Aaronson SA: Novel mechanism of Wnt signalling inhibition mediated by Dickkopf-1 interaction with LRP6/Arrow. Nat Cell Biol 3: 683-686, 2001.

3. Mao B, Wu W, Li Y, Hoppe D, Stannek P, Glinka A and Niehrs C: LDL-receptor-related protein 6 is a receptor for Dickkopf proteins. Nature 411: 321-325, 2001.

4. Mao B, Wu W, Davidson G, Marhold J, Li M, Mechler BM, Delius H, Hoppe D, Stannek P, Walter C, Glinka A and Niehrs C: Kremen proteins are Dickkopf receptors that regulate Wnt/betacatenin signalling. Nature 417: 664-667, 2002.

5. Kikuchi A: Tumor formation by genetic mutations in the components of the Wnt signaling pathway. Cancer Sci 94: 225-229, 2003.

6. Lustig B and Behrens J: The Wnt signaling pathway and its role in tumor development. J Cancer Res Clin Oncol 129: 199-221, 2003.

7. Reya $\mathrm{T}$ and Clevers $\mathrm{H}$ : Wnt signalling in stem cells and cancer. Nature 434: 843-850, 2005.

8. Kuphal S, Lodermeyer S, Bataille F, Schuierer M, Hoang BH and Bosserhoff AK: Expression of Dickkopf genes is strongly reduced in malignant melanoma. Oncogene 25: 5027-5036, 2006. 
9. Shou J, Ali-Osman F, Multani AS, Pathak S, Fedi P and Srivenugopal KS: Human Dkk-1, a gene encoding a Wnt antagonist, responds to DNA damage and its overexpression sensitizes brain tumor cells to apoptosis following alkylation damage of DNA. Oncogene 21: 878-889, 2002.

10. Bafico A, Liu G, Goldin L, Harris V and Aaronson SA: An autocrine mechanism for constitutive Wnt pathway activation in human cancer cells. Cancer Cell 6: 497-506, 2004.

11. Lee AY, He B, You L, Xu Z, Mazieres J, Reguart N, Mikami I, Batra S and Jablons DM: Dickkopf-1 antagonizes Wnt signaling independent of beta-catenin in human mesothelioma. Biochem Biophys Res Commun 323: 1246-1250, 2004.

12. Krupnik VE, Sharp JD, Jiang C, Robison K, Chickering TW, Amaravadi L, Brown DE, Guyot D, Mays G, Leiby K, Chang B, Duong T, Goodearl AD, Gearing DP, Sokol SY and McCarthy SA: Functional and structural diversity of the human Dickkopf gene family. Gene 238: 301-313, 1999.

13. Mao B and Niehrs C: Kremen2 modulates Dickkopf2 activity during Wnt/LRP6 signaling. Gene 302: 179-183, 2003.

14. Nozaki I, Tsuji T, Iijima O, Ohmura Y, Andou A, Miyazaki M, Shimizu N and Namba M: Reduced expression of REIC/Dkk-3 gene in non-small cell lung cancer. Int J Oncol 19: 117-121, 2001.

15. Kurose K, Sakaguchi M, Nasu Y, Ebara S, Kaku H, Kariyama R, Arao Y, Miyazaki M, Tsushima T, Namba M, Kumon $H$ and Huh NH: Decreased expression of REIC/Dkk-3 in human renal clear cell carcinoma. J Urol 171: 1314-1318, 2004.

16. Abarzua F, Sakaguchi M, Takaishi M, Nasu Y, Kurose K, Ebara S, Miyazaki M, Namba M, Kumon H and Huh NH: Adenovirus-mediated overexpression of REIC/Dkk-3 selectively induces apoptosis in human prostate cancer cells through activation of c-Jun-NH2-kinase. Cancer Res 65: 9617-9622, 2005.

17. Tanimoto R, Abrzua F, Sakaguchi M, Takaishi M, Nasu Y, Kumon H and Huh NH: REIC/Dkk-3 as a potential gene therapeutic agent against human testicular cancer. Int J Mol Med 19: 363-368, 2007.

18. Urano F, Wang X, Bertolotti A, Zhang Y, Chung P, Harding HP and Ron D: Coupling of stress in the ER to activation of JNK protein kinases by transmembrane protein kinase IRE1. Science 287: 664-666, 2000.
19. Tan Y, Dourdin N, Wu C, De Veyra T, Elce JS and Greer PA: Ubiquitous calpains promote caspase- 12 and JNK activation during endoplasmic reticulum stress-induced apoptosis. J Biol Chem 281: 16016-16024, 2006.

20. Park HS, Lee JS, Huh SH, Seo JS and Choi EJ: Hsp72 functions as a natural inhibitory protein of c-Jun $\mathrm{N}$-terminal kinase. EMBO J 20: 446-456, 2001.

21. Shim J, Lee H, Park J, Kim H and Choi EJ: A non-enzymatic p21 protein inhibitor of stress-activated protein kinases. Nature 381: 804-806, 1996.

22. Shim J, Park HS, Kim MJ, Park J, Park E, Cho SG, Eom SJ, Lee HW, Joe CO and Choi EJ: Rb protein down-regulates the stress-activated signals through inhibiting c-Jun N-terminal kinase/stress-activated protein kinase. J Biol Chem 275: 14107-14111, 2000.

23. Adler V, Yin Z, Fuchs SY, Benezra M, Rosario L, Tew KD, Pincus MR, Sardana M, Henderson CJ, Wolf CR, Davis RJ and Ronai Z: Regulation of JNK signaling by GSTp. EMBO J 18: 1321-1334, 1999.

24. Jaattela M: Overexpression of major heat shock protein hsp70 inhibits tumor necrosis factor-induced activation of phospholipase A2. J Immunol 151: 4286-4294, 1993.

25. Bellmann K, Jaattela M, Wissing D, Burkart V and Kolb H: Heat shock protein hsp70 overexpression confers resistance against nitric oxide. FEBS Lett 391: 185-188, 1996.

26. Gabai VL, Meriin AB, Mosser DD, Caron AW, Rits S, Shifrin VI and Sherman MY: Hsp70 prevents activation of stress kinases. A novel pathway of cellular thermotolerance. J Biol Chem 272: 18033-18037, 1997.

27. Mosser DD, Caron AW, Bourget L, Denis-Larose C and Massie B: Role of the human heat shock protein hsp70 in protection against stress-induced apoptosis. Mol Cell Biol 17: 5317-5327, 1997.

28. Buzzard KA, Giaccia AJ, Killender M and Anderson RL: Heat shock protein 72 modulates pathways of stress-induced apoptosis. J Biol Chem 273: 17147-17153, 1998

29. Jaattela M, Wissing D, Kokholm K, Kallunki T, Egeblad M: Hsp70 exerts its anti-apoptotic function downstream of caspase-3-like proteases, EMBO J 17: 6124-6134, 1998. 